\title{
Índice da sustentabilidade na Região do Submédio São Francisco, Pernambuco, Nordeste do Brasil
}

\section{Ariane Silva Cardoso ${ }^{1, *}$, Andreza dos Santos Rodrigues de Melo $^{2}$, Érika Alves Tavares Marques ${ }^{1}$, Maristela Casé ${ }^{3}$, Cláudia Ricardo de Oliveira ${ }^{1}$ e Maria do Carmo Martins Sobral $^{1}$}

\author{
${ }^{1}$ Universidade Federal de Pernambuco. Centro de Tecnologia e Geociências. Av. da \\ Arquitetura, S/No. Recife-PE, Brasil (CEP 50740-550). E-mail: \\ arianecardoso8@gmail.com. \\ ${ }^{2}$ Universidade Federal de Pernambuco. Centro de Filosofia e Ciências Humanas. Av. \\ da Arquitetura, S/№. Recife-PE, Brasil (CEP 50740-550). \\ ${ }^{3}$ Universidade do Estado da Bahia. Departamento de Educação. Campus VIII. Rua \\ da Gangorra, 503. Paulo Afonso-BA (CEP 486000-000).
}

Resumo. Os indicadores da sustentabilidade são um meio de verificar, quantificar e monitorar informações e ações que estão sendo realizadas, além de servir como base a índices que irão subsidiar estratégias para alcançar o desenvolvimento sustentável. A Região do Submédio São Francisco, situado na região semiárida entre os Estados da Bahia e Pernambuco, sofre influência de diversos impactos socioambientais e econômicos. Buscou-se neste artigo, através do Índice de Desenvolvimento Sustentável, avaliar a o perfil sustentável da Região do Submédio São Francisco. 0 Índice de Desenvolvimento Sustentável revelou performance aceitável de desenvolvimento sustentável para a Região de Desenvolvimento do Sertão de Itaparica, mas ainda longe de ser considerado ideal. A Região de Desenvolvimento do São Francisco obteve um Índice de Desenvolvimento Sustentável com performance de alerta. De modo geral, o índice final da Região de Desenvolvimento de Itaparica ficou superior ao índice final da Região de Desenvolvimento do São Francisco, o que demonstra que o índice não privilegia o desenvolvimento econômico frente aos outros indicadores. Pode-se observar grande desigualdade entre os municípios da Região de Desenvolvimento do São Francisco, o que influenciou no índice final mais baixo.

Palavras-chave: Indicadores; Desenvolvimento sustentável; Semiárido; Estratégias; Gestão.

Abstract. Sustainability index in the São Francisco Submiddle Region, Pernambuco, Northeast Brazil. Indicators of sustainability are a way to check, to quantify and to monitor the actions are being adopted for the development of a city, state or
Recebido

$03 / 10 / 2020$

Aceito

$27 / 08 / 2021$

Publicado

$31 / 08 / 2021$

Acesso aberto

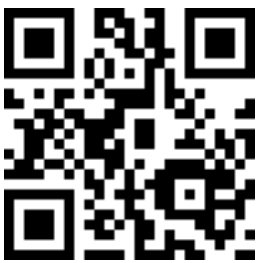

D 0000-0001-6252-6225

Ariane Silva Cardoso

(D) 0000-0002-5153-6548

Andreza dos Santos

Rodrigues de Melo 
country. In addition it is useful as a basis to calculate indexes that subsidize strategies to reach the sustainable development. The Submiddle São Francisco is located in the semiarid region between the States of Bahia and Pernambuco, is influenced by several environmental and economic impacts. In this work through of the Sustainable Development Index the sustainable profile of the region was evaluated. The Sustainable Development Index showed that the performance is acceptable for the Development Region Itaparica, but this index still is considered far from the ideal. The Development Region São Francisco was obtained as Sustainable Development Index alert performance. In general, the index for Development Region Itaparica is greater that the final index for Development Region São Francisco, this shows that the index does not take advantage for economic development front other Indicators. In Development Region São Francisco, it is observed more inequality between the municipalities and this influenced the low final index.

Keywords: Indicators; Sustainable Development; Semiarid; Strategies; Management.
(ㄱ) $0000-0002-6615-3347$

Érika Alves Tavares

Marques

(1) 0000-0001-9935-7912

Maristela Casé

다 0000-0003-4733-3534

Cláudia Ricardo de

Oliveira

(1) 0000-0001-8945-1606

Maria do Carmo

Martins Sobral

\section{Introdução}

0 crescente avanço das atividades humanas à base da exploração dos recursos naturais de forma descontrolada, leva cada vez mais a necessidade de dedicar-se ao uso sustentável desses recursos, pois vem ultrapassando o limite de resiliência dos ecossistemas e comprometendo a sustentabilidade dos mesmos e da vida no planeta.

Nas últimas décadas intensificaram-se os movimentos a respeito das problemáticas com foco na sustentabilidade ambiental (Drahein et al., 2020). Em 1972, a Organização das Nações Unidas (ONU) realizou a Conferência de Estocolmo, a fim de discutir os problemas enfrentados pela degradação, partindo daí a raiz da ideia do novo modelo de desenvolvimento a ser adotado, buscando o desenvolvimento sustentável nas atividades econômicas e na exploração de recursos (Gomes et al., 2005).

Embora os conceitos de "Crescimento" e "Desenvolvimento" sejam próximos entre si, é importante esclarecer diferenças. O Crescimento diz respeito ao aumento de produção, de bens que atendam às necessidades humanas. 0 conceito de Desenvolvimento é ampliado e abrange, além da magnitude da expansão da produção, a natureza e a qualidade deste crescimento e como isto afeta positivamente as condições de vida dos habitantes de um país (Ramos, 2016).

O termo "desenvolvimento sustentável" surgiu em 1987, no relatório durante a World Commission of Environment and Development (WCED), e significa explorar os recursos naturais de maneira equilibrada, de modo que as necessidades do presente sejam supridas, sem comprometer as necessidades das futuras gerações (Munro, 1991).

Desenvolvimento Sustentável é definido pela Comissão Mundial sobre o Meio Ambiente e Desenvolvimento (1988, p. 49) como:

[...] um processo de transformação no qual a exploração dos recursos, a direção dos investimentos, a orientação do desenvolvimento tecnológico e a mudança institucional se harmonizam e reforçam o potencial presente e futuro, a fim de atender às necessidades e aspirações humanas. 
O desenvolvimento e sustentabilidade ambiental requerem o completo replanejamento de organizações e estratégias uma vez que visa a promover melhor qualidade de vida para a população, e com base que esse conceito envolve, sobretudo, as esferas ambiental, econômica, social e institucional, de acordo com Krama (2009), modelos de indicador de sustentabilidade que abrangem essas esferas de modo interdisciplinar são necessários na tentativa de mensurar a complexidade da realidade no âmbito do desenvolvimento.

O conceito de desenvolvimento sustentável passou por diversas transformações (Barbieri, 1997). Considerando a evolução do conceito nos últimos 50 anos, o desenvolvimento sustentável pode ser caracterizado como: econômico, social, político, cultural e institucional. Dessa forma, afirma-se que o desenvolvimento sustentável é social e ético, mas condicionado aos fatores ambientais, institucionais e à viabilidade econômica (Sachs, 2004).

Para se atingir um desenvolvimento sustentável, torna-se necessário examinar as dimensões sociais, econômicas, ecológicas, e culturais - numa visão multidisciplinar - com a finalidade de analisar as variáveis e todo o espectro de perspectivas que envolvem o imenso desafio de atender às necessidades materiais e imateriais da sociedade de uma forma equitativa (Cipolat et al., 2010). Considerando que o desenvolvimento varia ao longo do tempo, é necessário monitorar periodicamente os indicadores, detectando as vulnerabilidades referentes às diferentes dimensões, fornecendo informações essenciais para o planejamento das políticas públicas.

Os indicadores da sustentabilidade são meios de verificar, quantificar e monitorar informações e ações que estão sendo realizadas, nas diferentes dimensões, além de servir como base aos índices que irão subsidiar estratégias no envolvimento do desenvolvimento sustentável pelos gestores e na formulação de políticas públicas (Krama, 2009; Goulart e Pietrafesa, 2020; Santos et al., 2020). E sua aplicação é imprescindível, uma vez que, os impactos das exploração dos recursos naturais são contínuos (Carvalho et al., 2020).

No contexto do desenvolvimento sustentável, um conjunto de indicadores de sustentabilidade tem como objetivo indicar a comunidade os riscos e tendências do desenvolvimento, estabelecendo planejamento e estratégias de combate aos riscos para o futuro (Guimarães, 1998). Uma das características essenciais dos indicadores para sua funcionabilidade é a identidade numérica. Sem essa faceta quantitativa, os indicadores são mais subjetivos e podem perder, inclusive, sua aplicabilidade (Pereira et al., 2015).

A região do Submédio São Francisco, situado na região semiárida, sofre influência de diversos impactos socioambientais e econômicos, sobretudo, pela utilização dos recursos hídricos e do uso e ocupação do solo. Em face desses aspectos vislumbra-se a importância de estudos que busquem mensurar os índices de sustentabilidade locais. Especialmente, por se tratar de uma região com diversos conflitos pelo uso dos recursos hídricos, sem controle do equilíbrio entre o crescimento econômico simultaneamente à sustentabilidade do uso dos recursos naturais (Sobral et al., 2009).

Este estudo pretende analisar os principais indicadores que remetem ao índice de sustentabilidade na região do Submédio São Francisco, no Estado de Pernambuco, Brasil. Os indicadores em questão referem-se às dimensões ambiental, econômica, social e institucional. A partir dessa análise pretende-se apresentar um panorama da conjuntura do desenvolvimento sustentável na região.

\section{Material e métodos}

\section{Delimitação da área de estudo}

A Região Hidrográfica do São Francisco abrange vários estados, e, devido à sua extensão e aos diferentes ambientes que percorre, está subdividida em quatro regiões fisiográficas, que são Alto, Médio, Submédio e Baixo São Francisco (MMA, 2006). 
A Região do Submédio São Francisco estende-se pelos Estados da Bahia e Pernambuco, percorrendo $686 \mathrm{~km}$ com desnível de $250 \mathrm{~m}$, entre os Municípios de Remanso e Paulo Afonso, no Estado da Bahia, região a qual foi foco para o início de instalação de hidroelétricas. Nesta região, a Bacia do Rio São Francisco, apresenta represamento por meio das Usinas de Sobradinho, Luiz Gonzaga (também chamado de Reservatório Itaparica) e do Complexo de Paulo Afonso, formado pelas usinas Paulo Afonso I, II, III, IV e Apolônio Sales (Moxotó) (CHESF, 2010). A população corresponde a um total de 15,2\% dos habitantes da bacia. 0 clima predominante é o semiárido, a precipitação média anual é de $693 \mathrm{~mm}$, com temperatura média de $27{ }^{\circ} \mathrm{C}$ e seu trecho principal possui total de $550 \mathrm{~km}$, com área de $110.446 \mathrm{~km}^{2}$ (17\%) (Brasil, 2006).

A fim de representar a Região do Submédio São Francisco, para a área de estudo foram selecionados os seguintes municípios situados no Estado de Pernambuco: Belém do São Francisco (BSF), Carnaubeira da Penha (CAR), Floresta (FLO), Itacuruba (ITA), Jatobá (JAT), Petrolândia (PET) e Tacaratu (TAC), situados na área de abrangência da Região de Desenvolvimento do Sertão de Itaparica, e Afrânio (AFR), Cabrobó (CAB), Dormentes (DOR), Lagoa Grande (LAG), Orocó (ORO), Petrolina (PET), Santa Maria da Boa Vista (SBV), situados na Região de Desenvolvimento do Sertão do São Francisco.

\section{Procedimento metodológico}

0 método de abordagem utilizado no estudo teve como base a pesquisa exploratória, deste modo, refere-se a um artigo teórico, onde os dados secundários foram obtidos a partir de levantamento bibliográfico sobre o tema. Buscou-se neste estudo, através da realização de um índice indutivo e sistemático de desenvolvimento sustentável avaliar a o perfil sustentável da Região do Submédio São Francisco.

0 procedimento de análise adotado abrangeu as seguintes etapas: seleção de dados secundários; aplicação do modelo de indicadores e transformação das variáveis para valores através da metodologia proposta por Martins; Cândido (2008).

O Índice de Desenvolvimento Sustentável para Municípios (IDSM) contempla um conjunto de indicadores distribuídos nas dimensões, que possibilita medir o nível de sustentabilidade de uma região geográfica. No Brasil, o IBGE publica um relatório com Indicadores de Desenvolvimento Sustentável desde 2002, que servem como um importante subsídio para analisar o desenvolvimento socioeconômico e ambiental do país (Lopes et al., 2017).

Na escolha dos indicadores primários, utilizaram-se apenas dados disponíveis para os municípios escolhidos, empregando como arcabouço norteador dos indicadores a serem observados, os Indicadores de Desenvolvimento Sustentável do Instituto Brasileiro de Geografia e Estatística (IBGE, 2015) e a proposta adaptada de Martins e Cândido (2008) e Waquil et al. (2010), e como fonte de dados o próprio IBGE, com dados entre os anos de 2010 a 2014. As dimensões e seus respectivos indicadores da sustentabilidade utilizados foram (Martins e Cândido, 2008):

1 - Dimensão ambiental: Consumo médio diário per capita de água (tratada) $\mathrm{m}^{3}$ Acesso ao sistema de abastecimento de água (unidade)

Tipo de esgotamento sanitário por domicílio

2 - Dimensão social: Densidade demográfica (hab. $/ \mathrm{km}^{2}$ )

Taxa de urbanização

Esperança de vida ao nascer

Taxa de mortalidade infantil

Índice de Desenvolvimento Humano Municipal - IDHM

Escolarização - pessoas de 10 anos ou mais por nível de instrução

Estabelecimento de Saúde (SUS) 
3 - Dimensão econômica: Produto Interno Bruto per capita (R\$)

Renda familiar per capita em salários mínimos (R\$)

Índice de Gini de distribuição do rendimento

4 - Dimensão institucional: Participação nas Eleições

Número de Conselhos Municipais

Transferências Intergovernamentais da União

Os resultados encontrados para cada indicador são transformados em um índice, a partir do cálculo desenvolvido pelo Instituto Interamericano de Cooperação para à Agricultura (IICA), descrito por Waquil et al. (2010).

Quando a relação é positiva segue a Equação 1:

$$
\mathrm{I}=(\mathbf{x}-\mathbf{m}) /(\mathbf{M}-\mathbf{m})
$$

(Equação 1)

A relação é considerada positiva quando verificado que, quanto maior o indicador melhor será o índice, e quanto menor o indicador, pior será o índice.

Quando a relação é negativa segue a Equação 2:

$$
\mathbf{I}=(\mathbf{M}-\mathbf{x}) /(\mathbf{M}-\mathbf{m})
$$

(Equação 2)

Onde:

I = índice calculado para cada Estado e municípios analisados;

$\mathrm{x}$ = valor de cada variável em cada Estado ou Município;

$\mathrm{m}=$ valor mínimo identificado nessas localidades; e

$\mathrm{M}=$ valor máximo identificado nessas localidades.

A relação é considerada negativa quando verificado que, quanto maior o indicador, pior será o índice, quanto menor o indicador, melhor será o índice.

Esta metodologia combina os valores das variáveis numa escala com variação entre 0 e 1 , onde o valor mínimo é 0 (zero) e o valor máximo é 1 (um) (Tabela 1 ). Após o cálculo do índice para cada indicador, dentro de suas respectivas dimensões, o valor final de cada dimensão é utilizado para calcular o Índice de Desenvolvimento Sustentável para Municípios do Submédio São Francisco.

Tabela 1. Classificação e representação dos índices em níveis de sustentabilidade.

\begin{tabular}{|c|c|}
\hline Índice (0-1) & Performance \\
\hline $0,7501-1,000$ & Ideal \\
\hline $0,5001-0,7500$ & Aceitável \\
\hline $0,2501-0,5000$ & Alerta \\
\hline $0,0000-0,2500$ & Crítica \\
\hline
\end{tabular}

Fonte: Martins e Cândido (2008).

Após a transformação das variáveis em índices, foi realizada a agregação desses índices por dimensão, através da média aritmética, chegando-se ao Índice de Desenvolvimento Sustentável para Municípios Social, Econômico, Político-institucional e Ambiental. 0 Índice de Desenvolvimento Sustentável para Municípios Final foi calculado através da média aritmética dos Índices de Desenvolvimento Sustentável para Municípios das dimensões. 


\section{Resultados e discussão}

\section{Dimensão ambiental}

Os resultados analisados a partir dos indicadores voltados à dimensão ambiental para os municípios da área de abrangência das Regiões de Desenvolvimento do Sertão de Itaparica (Tabela 2) e do Sertão do São Francisco (Tabela 3), revelaram que as variáveis analisadas demostram um perfil de insustentabilidade ambiental para ambas regiões de desenvolvimento.

Na Região de Desenvolvimento do Sertão de Itaparica podemos observar que a relação entre acesso à água tratada e o consumo médio da região se encontram num panorama inquietante, de alerta para os usuários e Poder Público, quanto à capacidade de suporte dos recursos hídricos e o grau de resiliência desse ecossistema, sobretudo por se tratar de uma região com usos múltiplos da água, destacando as áreas de agricultura irrigada nos Municípios de Floresta, Petrolândia e Belém do São Francisco. Outra variável em debate é o tipo de esgotamento sanitário, classificado assim como os demais indicadores, com status de alerta, revelando as condições precárias de destinação dos resíduos gerados na região.

Analisando os municípios da área de estudo, apenas os Municípios de Floresta e Jatobá, possuem a condição de Aceitável, e Petrolândia, a condição de Ideal, para o acesso ao sistema de abastecimento de água (Tabela 2). Entretanto, os demais municípios que estão em condição de Alerta ou Crítica, também se encontram em áreas que estão próximas a um curso d'água, como Rio São Francisco, de grande porte, perene e de extrema importância para região. Esta peculiaridade, de se encontrar próximo a uma bacia hidrográfica, não foi capaz de garantir acesso a água a todos.

O consumo de água, apesar da deficiência na distribuição deste recurso nos referidos municípios, encontra-se na maior parte em condição caracterizada como Crítica, chamando atenção por tratar-se de uma região semiárida, com clima cada vez mais influenciado pelas mudanças climáticas, baixos índices pluviométricos, induzindo a uma redução frequente da vazão dos reservatórios a montante, os quais controlam a entrada de água na Bacia do São Francisco, responsável pelo abastecimento da região, e ainda tratando-se de uma área propensa a conflitos por usos múltiplos da água.

0 adequado tipo de esgotamento sanitário por domicílios considerado Ideal nos Municípios de Itacuruba, Jatobá e Petrolândia, mostram que apesar do ineficiente uso sustentável da água, a apropriada destinação dos resíduos domiciliares vem ganhando espaço e interesse nessa região.

Assim como, a Região de Desenvolvimento do Sertão de Itaparica, a Região de Desenvolvimento do Sertão do São Francisco, encontra-se num panorama de Alerta para o consumo da água, desde quantitativo como qualitativo, e destinação dos seus resíduos, apresentando índices ainda mais críticos.

Apesar da maior parte dos municípios situarem-se às margens do Rio São Francisco, o acesso à água tratada ainda é bastante precário, com exceção de Petrolina e Cabrobó, os demais municípios da referida RD, encontram-se em condição Crítica quanto ao acesso ao sistema de abastecimento de água, sobretudo considerando a correlação com o consumo médio per capita de água nessas localidades, que também se encontram em condição Crítica (Tabela 3). 
Tabela 2. Índice ambiental nos municípios na área de abrangência da Região de Desenvolvimento do Sertão de Itaparica.

\begin{tabular}{|c|c|c|c|c|c|c|c|c|}
\hline \multicolumn{8}{|c|}{ IDSM Ambiental - RD Sertão de Itaparica } & \multirow[b]{2}{*}{ ITA } \\
\hline Indicadores & BSF & CAR & FLO & ITA & JAT & PET & TAC & \\
\hline $\begin{array}{l}\text { Consumo médio } \\
\text { per capita de } \\
\text { água (tratada por } \\
\text { dia) } \mathrm{m}^{3}\end{array}$ & $\begin{array}{c}0,3949 \\
\text { Alerta }\end{array}$ & $\begin{array}{l}0,0000 \\
\text { Crítica }\end{array}$ & $\begin{array}{l}0,2184 \\
\text { Crítica }\end{array}$ & $\begin{array}{l}0,1303 \\
\text { Crítica }\end{array}$ & $\begin{array}{l}0,2030 \\
\text { Crítica }\end{array}$ & $\begin{array}{c}1,0000 \\
\text { Ideal }\end{array}$ & $\begin{array}{l}0,1218 \\
\text { Crítica }\end{array}$ & $\begin{array}{c}0,2955 \\
\text { Alerta }\end{array}$ \\
\hline $\begin{array}{l}\text { Acesso ao } \\
\text { sistema de } \\
\text { abastecimento de } \\
\text { água (unidades) }\end{array}$ & $\begin{array}{l}0,4666 \\
\text { Alerta }\end{array}$ & $\begin{array}{l}0,0000 \\
\text { Crítica }\end{array}$ & $\begin{array}{c}0,6257 \\
\text { Aceitável }\end{array}$ & $\begin{array}{l}0,1000 \\
\text { Crítica }\end{array}$ & $\begin{array}{c}0,6167 \\
\text { Aceitável }\end{array}$ & $\begin{array}{l}1,000 \\
\text { Ideal }\end{array}$ & $\begin{array}{l}0,2690 \\
\text { Crítica }\end{array}$ & $\begin{array}{l}0,4397 \\
\text { Alerta }\end{array}$ \\
\hline \multicolumn{9}{|c|}{ Tipo de esgotamento sanitário por domicílio } \\
\hline Adequado & $\begin{array}{c}0,4168 \\
\text { Alerta }\end{array}$ & $\begin{array}{l}0,0000 \\
\text { Crítica }\end{array}$ & $\begin{array}{l}\text { 0,4202 } \\
\text { Alerta }\end{array}$ & $\begin{array}{l}1,0000 \\
\text { Ideal }\end{array}$ & $\begin{array}{c}0,7771 \\
\text { Ideal }\end{array}$ & $\begin{array}{c}0,8124 \\
\text { Ideal }\end{array}$ & $\begin{array}{l}0,0470 \\
\text { Crítica }\end{array}$ & $\begin{array}{c}0,4962 \\
\text { Alerta }\end{array}$ \\
\hline Semi-adequado & $\begin{array}{c}0,4376 \\
\text { Alerta }\end{array}$ & $\begin{array}{c}0,8741 \\
\text { Ideal }\end{array}$ & $\begin{array}{c}0,3759 \\
\text { Alerta }\end{array}$ & $\begin{array}{c}1,0000 \\
\text { Ideal }\end{array}$ & $\begin{array}{c}0,7751 \\
\text { Ideal }\end{array}$ & $\begin{array}{c}0,5164 \\
\text { Aceitável }\end{array}$ & $\begin{array}{l}0,0000 \\
\text { Crítica }\end{array}$ & $\begin{array}{c}0,5684 \\
\text { Aceitável }\end{array}$ \\
\hline Inadequado & $\begin{array}{c}0,6264 \\
\text { Aceitável }\end{array}$ & $\begin{array}{l}0,0000 \\
\text { Crítica }\end{array}$ & $\begin{array}{c}0,6575 \\
\text { Aceitável }\end{array}$ & $\begin{array}{c}0,9626 \\
\text { Ideal }\end{array}$ & $\begin{array}{c}0,8476 \\
\text { Ideal }\end{array}$ & $\begin{array}{c}1,0000 \\
\text { Ideal }\end{array}$ & $\begin{array}{c}0,4405 \\
\text { Alerta }\end{array}$ & $\begin{array}{c}0,6478 \\
\text { Aceitável }\end{array}$ \\
\hline $\begin{array}{l}\text { IDS ambiental } \\
\text { médio }\end{array}$ & & & & & & & & $\begin{array}{l}0,4895 \\
\text { Alerta }\end{array}$ \\
\hline
\end{tabular}

Legenda: BSF - Belém de São Francisco; CAR - Carnaubeira da Penha; FLO - Floresta; IDS - Índice de Desenvolvimento Sustentável; IDSM - Índice de Desenvolvimento Sustentável para Municípios; ITA - Itacuruba; JAT - Jatobá; PET - Petrolândia; TAC - Tacaratu; RD - Região de Desenvolvimento; RD ITA - Região de Desenvolvimento do Sertão de Itaparica.

Os dados aqui apresentados demonstram, mais uma vez, o estado de insustentabilidade ambiental, e também sanitário, visto que além do acesso à água, a qualidade da mesma precisa ser levada em consideração. Se estas populações se encontram com baixo acesso à água, outros meios estão sendo procurados para obter este recurso vital à vida. Meios estes que não garantem a qualidade para consumo humano.

O Município de Petrolina foi a única apresentando indicadores caracterizados como Ideal. 0 indicador voltado à destinação dos resíduos domiciliares, tipo de esgotamento sanitário por domicílio, foi caracterizado no nível adequado como Ideal, apenas em Cabrobó e Petrolina. Chamando atenção para o município de Afrânio, onde foi caracterizado como condição Crítica, em nível inadequado, representando a região de desenvolvimento como a localidade que exibe menor infraestrutura de esgotamento sanitário.

Apesar, da exposição de resultados em níveis caracterizados como Aceitável e Ideal, para ambas as regiões de desenvolvimento, esse indicador considera apenas o tipo de esgotamento nos domicílios, portanto, dados referentes à destinação final dos resíduos domésticos dessas regiões, precisam ser disponibilizados com maior transparência pelo Poder Público e fiscalizados pelos órgãos competentes e pela sociedade civil. Uma vez que, não adianta somente controlar o manejo nas residências, mas também o tratamento desses efluentes, para que ao menos sejam lançados nos corpos hídricos ou reutilizados. 
Tabela 3. Índice Ambiental nos municípios na área de abrangência da Região de Desenvolvimento do Sertão do São Francisco.

\begin{tabular}{|c|c|c|c|c|c|c|c|}
\hline \multicolumn{7}{|c|}{ IDSM Ambiental - RD Sertão do São Francisco } & \multirow[b]{2}{*}{ RD SF } \\
\hline Indicadores & AFR & CAB & DOR & LAG & ORO & PET & \\
\hline $\begin{array}{l}\text { Consumo médio } \\
\text { per capita de } \\
\text { água (tratada por } \\
\text { dia) }\end{array}$ & $\begin{array}{l}0,0048 \\
\text { Crítica }\end{array}$ & $\begin{array}{l}0,1000 \\
\text { Crítica }\end{array}$ & $\begin{array}{l}0,0000 \\
\text { Crítica }\end{array}$ & $\begin{array}{l}0,0602 \\
\text { Crítica }\end{array}$ & $\begin{array}{l}0,0218 \\
\text { Crítica }\end{array}$ & $\begin{array}{l}1,0000 \\
\text { Ideal }\end{array}$ & $\begin{array}{l}0,1850 \\
\text { Crítica }\end{array}$ \\
\hline $\begin{array}{l}\text { Acesso ao } \\
\text { sistema de } \\
\text { abastecimento de } \\
\text { água }\end{array}$ & $\begin{array}{l}0,0015 \\
\text { Crítica }\end{array}$ & $\begin{array}{l}0,0678 \\
\text { Crítica }\end{array}$ & $\begin{array}{l}0,0000 \\
\text { Crítica }\end{array}$ & $\begin{array}{l}0,0797 \\
\text { Crítica }\end{array}$ & $\begin{array}{l}0,0000 \\
\text { Crítica }\end{array}$ & $\begin{array}{c}1,0000 \\
\text { Ideal }\end{array}$ & $\begin{array}{l}0,1723 \\
\text { Crítica }\end{array}$ \\
\hline \multicolumn{8}{|c|}{ Tipo de esgotamento sanitário por domicílio } \\
\hline Adequado & $\begin{array}{l}0,0000 \\
\text { Crítica }\end{array}$ & $\begin{array}{c}0,7771 \\
\text { Ideal }\end{array}$ & $\begin{array}{l}0,1780 \\
\text { Crítica }\end{array}$ & $\begin{array}{l}0,4086 \\
\text { Alerta }\end{array}$ & $\begin{array}{c}0,2826 \\
\text { Alerta }\end{array}$ & $\begin{array}{l}1,0000 \\
\text { Ideal }\end{array}$ & $\begin{array}{l}0,4238 \\
\text { Alerta }\end{array}$ \\
\hline $\begin{array}{l}\text { Semi- } \\
\text { adequado }\end{array}$ & $\begin{array}{c}0,7333 \\
\text { Aceitável }\end{array}$ & $\begin{array}{c}0,9705 \\
\text { Ideal }\end{array}$ & $\begin{array}{l}0,0853 \\
\text { Crítica }\end{array}$ & $\begin{array}{l}0,4981 \\
\text { Alerta }\end{array}$ & $\begin{array}{l}0,0000 \\
\text { Crítica }\end{array}$ & $\begin{array}{c}1,0000 \\
\text { Ideal }\end{array}$ & $\begin{array}{c}0,519 \\
\text { Aceitável }\end{array}$ \\
\hline Inadequado & $\begin{array}{l}0,0000 \\
\text { Crítica }\end{array}$ & $\begin{array}{c}0,7511 \\
\text { Ideal }\end{array}$ & $\begin{array}{c}0,6298 \\
\text { Aceitável }\end{array}$ & $\begin{array}{c}0,6322 \\
\text { Aceitável }\end{array}$ & $\begin{array}{c}0,8080 \\
\text { Ideal }\end{array}$ & $\begin{array}{c}1,0000 \\
\text { Ideal }\end{array}$ & $\begin{array}{c}0,6344 \\
\text { Aceitável }\end{array}$ \\
\hline $\begin{array}{l}\text { IDS ambiental } \\
\text { Médio }\end{array}$ & & & & & & & $\begin{array}{l}\text { 0,3870 } \\
\text { Alerta }\end{array}$ \\
\hline
\end{tabular}

Legenda: AFR - Afrânio; CAB - Cabrobó; DOR - Dormentes; IDS - Índice de Desenvolvimento Sustentável; IDSM - Índice de Desenvolvimento Sustentável para Municípios; LAG - Lagoa Grande; ORO - Orocó; PET - Petrolina; RD - Região de Desenvolvimento; RD SF - Região de Desenvolvimento do Sertão do São Francisco.

Diante dos resultados apresentados e da grande demanda pelo recurso hídrico na região versus a disponibilidade de água tratada, ações voltadas aos usos múltiplos da água deverão ponderar a capacidade de suporte do ambiente aquático e se este conseguirá manter a capacidade de resiliência e autopoiese, a fim de analisar a capacidade hídrica para atender às necessidades humanas e manter o ecossistema aquático em equilíbrio (Francelino et al., 2005). Além do cuidado com o lançamento de efluentes domésticos, que se encontram sem condição de Alerta nas duas regiões de desenvolvimento em estudo, que como ciclo natural, impactará tanto no ecossistema aquático assim como no cotidiano humano.

Monitoramento ambiental realizado no Reservatório de Itaparica, pela Companhia Hidroelétrica do São Francisco (CHESF), nos períodos de 2010 e 2013, revelam que nesse intervalo de tempo ocorreu diminuição do nível da água no reservatório, a profundidade média no ano de 2010 era de aproximadamente 21 m, já em 2013, a média caiu para aproximadamente $15 \mathrm{~m}$ (CHESF, 2010; 2014). Esses dados demonstram o panorama hídrico atual na região e nos leva a refletir acerca da sustentabilidade desse recurso frente às mudanças climáticas e os seus usos múltiplos.

\section{Dimensão econômica}

Os indicadores utilizados para dimensionar a sustentabilidade econômica no Submédio São Francisco, revelaram níveis sustentáveis mais favoráveis para ambas as regiões de desenvolvimento, no parâmetro Índice de Gini de distribuição do rendimento, sendo classificado como Aceitável (Tabela 4 e Tabela 5). Este índice é uma medida da igualdade da distribuição de renda (Rocha et al., 2010), onde seu resultado consiste em um número entre 0 e 1 , onde 0 corresponde à maior igualdade, por exemplo: toda a população recebe o mesmo salário e 1 corresponde à maior desigualdade, onde uma pessoa recebe 
todo o rendimento e as restantes não recebem nada (Araújo e Morais, 2014). Entretanto, o Produto Interno Bruto (PIB), encontra-se caracterizados em situação de Alerta, em ambas as regiões de desenvolvimento, e a renda per capita, na Região de Desenvolvimento do Sertão do São Francisco, em nível Crítico.

A redução da desigualdade são escopos norteadores de políticas públicas que visam à promoção da igualdade no país, com intuito de diminuir a situação de pobreza através do aumento da renda dos menos favorecidos financeiramente (Rocha et al., 2010).

As condições de renda da população geram diversas limitações na esfera da saúde, da nutrição, social, cultural, econômica, educacional e trabalhista, como a inserção de crianças e adolescentes no mercado de trabalho, e como um efeito em cadeia, refletindo no acesso e comprometimento escolar, elevando o percentual de analfabetos e diferenças de escolaridade, que mais adiante influenciará negativamente na inserção em postos de trabalho melhor remunerados, além de problemas de moradias adequadas, saneamento básico, segurança e participação política (Rocha et al., 2010).

Analisando a Região de Desenvolvimento do Sertão de Itaparica, podemos observar que em Belém do São Francisco, Jatobá e Petrolândia, apesar da renda per capita serem caracterizadas como Ideal, o Índice de Gini encontram-se classificados como, Crítica, Alerta e Alerta, respectivamente (Tabela 4). Demonstrando que, apesar da renda estar em condição favorável nessas localidades, a distribuição da mesma não ocorre de maneira sustentável. Em municípios como Carnaubeira da Penha, Jatobá e Tacaratu, o PIB encontra-se em condição caracterizada como Crítica, chamando atenção especialmente para Tacaratu, que apesar do PIB e da renda estarem em condição Crítica, a distribuição de renda entre a população local é considerada Ideal, em relação aos demais municípios da região de desenvolvimento.

Tabela 4. Índice Econômico nos municípios na área de abrangência da Região de Desenvolvimento do Sertão de Itaparica.

\begin{tabular}{|c|c|c|c|c|c|c|c|c|}
\hline \multicolumn{8}{|c|}{ IDSM - Econômico RD Sertão de Itaparica } & \multirow[b]{2}{*}{ RD ITA } \\
\hline Indicadores & BSF & CAR & FLO & ITA & JAT & PET & TAC & \\
\hline $\begin{array}{l}\text { Produto } \\
\text { Interno bruto } \\
\text { per capita } \\
\text { (R\$) }\end{array}$ & $\begin{array}{c}1,0000 \\
\text { Ideal }\end{array}$ & $\begin{array}{l}0,0000 \\
\text { Alerta }\end{array}$ & $\begin{array}{c}0,5363 \\
\text { Aceitável }\end{array}$ & $\begin{array}{c}0,3629 \\
\text { Alerta }\end{array}$ & $\begin{array}{c}0,1385 \\
\text { Alerta }\end{array}$ & $\begin{array}{c}0,6645 \\
\text { Aceitável }\end{array}$ & $\begin{array}{l}0,0111 \\
\text { Crítica }\end{array}$ & $\begin{array}{l}0,3876 \\
\text { Alerta }\end{array}$ \\
\hline $\begin{array}{l}\text { Renda per } \\
\text { capita (R\$) }\end{array}$ & $\begin{array}{c}1,0000 \\
\text { Ideal }\end{array}$ & $\begin{array}{l}0,0000 \\
\text { Crítica }\end{array}$ & $\begin{array}{c}0,7476 \\
\text { Aceitável }\end{array}$ & $\begin{array}{c}0,5416 \\
\text { Aceitável }\end{array}$ & $\begin{array}{c}0,9177 \\
\text { Ideal }\end{array}$ & $\begin{array}{c}0,9268 \\
\text { Ideal }\end{array}$ & $\begin{array}{l}0,1866 \\
\text { Crítica }\end{array}$ & $\begin{array}{c}0,6172 \\
\text { Aceitável }\end{array}$ \\
\hline $\begin{array}{l}\text { Índice de Gini } \\
\text { (distribuição } \\
\text { do } \\
\text { rendimento) }\end{array}$ & $\begin{array}{l}0,0000 \\
\text { Crítica }\end{array}$ & $\begin{array}{c}0,4117 \\
\text { Alerta }\end{array}$ & $\begin{array}{c}0,6470 \\
\text { Aceitável }\end{array}$ & $\begin{array}{l}1,0000 \\
\text { Ideal }\end{array}$ & $\begin{array}{c}0,3529 \\
\text { Alerta }\end{array}$ & $\begin{array}{c}0,4705 \\
\text { Alerta }\end{array}$ & $\begin{array}{c}0,8225 \\
\text { Ideal }\end{array}$ & $\begin{array}{c}0,5292 \\
\text { Aceitável }\end{array}$ \\
\hline $\begin{array}{l}\text { IDS } \\
\text { econômico } \\
\text { médio } \\
\end{array}$ & & & & & & & & $\begin{array}{c}0,5313 \\
\text { Aceitável }\end{array}$ \\
\hline
\end{tabular}

Legenda: BSF - Belém de São Francisco; CAR - Carnaubeira da Penha; FLO - Floresta; IDS - Índice de Desenvolvimento Sustentável; IDSM - Índice de Desenvolvimento Sustentável para Municípios; ITA - Itacuruba; JAT - Jatobá; PET - Petrolândia; TAC - Tacaratu; RD - Região de Desenvolvimento; RD ITA - Região de Desenvolvimento do Sertão de Itaparica.

O Município de Floresta é o único com situação mais aproximada de uma posição sustentável, com indicadores caracterizados como Aceitável. Possui sua economia local voltada para agricultura de sequeiro e irrigada, pecuária e aquicultura. Apesar do clima

Rev. Bras. Gest. Amb. Sustent., 2021, vol. 8, n. 19, p. 1089-1108. 
semiárido, a sua localização à margem do reservatório de Itaparica, é um dos fatores que proporciona condições para o desenvolvimento dessas atividades, além de investimento em infraestrutura. As principais atividades desenvolvidas na região são a agricultura de sequeiro, com predomínio de cultivo para subsistência de feijão e milho, a agricultura irrigada com destaque para melão, melancia, cebola e tomate, que emprega melhor tecnologia e maior relevância para economia local e a pecuária, de forma extensiva.

Na Região de Desenvolvimento do Sertão do São Francisco, apenas no Município de Dormentes, o Índice de Gini é considerado Ideal, entretanto, seu PIB e renda estão em situação Crítica para o desenvolvimento econômico da região (Tabela 5). Os demais municípios encontram-se em situação semelhante à Região de Desenvolvimento do Sertão de Itaparica, com PIB e renda per capita em situação caracterizada como Crítica e Alerta, apenas Petrolina, localidade de maior porte, com maior presença de postos de trabalho, através de maior concentração e infraestrutura voltada para agricultura irrigada, entre outras atividades, como as do terceiro setor, apresenta-se caracterizada com esses indicadores em níveis Ideais. Apesar desses resultados, a desigualdade na distribuição de renda, é a mais acentuada e menos sustentável. Com o maior poder econômico na mão de poucos indivíduos.

Tabela 5. Índice Econômico nos municípios na área de abrangência da Região de Desenvolvimento do Sertão do São Francisco.

\begin{tabular}{|c|c|c|c|c|c|c|c|c|}
\hline \multicolumn{8}{|c|}{ IDSM-econômico RD Sertão do São Francisco } & \multirow[b]{2}{*}{ RD SF } \\
\hline Indicadores & AFR & CAB & DOR & LAG & ORO & PET & SBV & \\
\hline $\begin{array}{l}\text { Produto } \\
\text { Interno bruto } \\
\text { per capita } \\
(\mathrm{R} \$)\end{array}$ & $\begin{array}{l}0,0000 \\
\text { Crítica }\end{array}$ & $\begin{array}{l}0,3771 \\
\text { Alerta }\end{array}$ & $\begin{array}{c}0,1827 \\
\text { Ideal }\end{array}$ & $\begin{array}{l}0,4868 \\
\text { Ideal }\end{array}$ & $\begin{array}{l}0,3633 \\
\text { Alerta }\end{array}$ & $\begin{array}{l}1,000 \\
\text { Ideal }\end{array}$ & $\begin{array}{c}0,4157 \\
\text { Alerta }\end{array}$ & $\begin{array}{c}0,4037 \\
\text { Alerta }\end{array}$ \\
\hline $\begin{array}{l}\text { Renda per } \\
\text { capita }(\mathrm{R} \$)\end{array}$ & $\begin{array}{c}0,2410 \\
\text { Alerta }\end{array}$ & $\begin{array}{l}0,1936 \\
\text { Crítica } \\
\end{array}$ & $\begin{array}{l}0,0875 \\
\text { Crítica } \\
\end{array}$ & $\begin{array}{l}0,1906 \\
\text { Crítica } \\
\end{array}$ & $\begin{array}{l}0,0000 \\
\text { Crítica } \\
\end{array}$ & $\begin{array}{l}1,0000 \\
\text { Ideal }\end{array}$ & $\begin{array}{l}0,1141 \\
\text { Crítica }\end{array}$ & $\begin{array}{l}0,2300 \\
\text { Crítica } \\
\end{array}$ \\
\hline $\begin{array}{l}\text { Índice de Gini } \\
\text { (distribuição } \\
\text { do } \\
\text { rendimento) }\end{array}$ & $\begin{array}{c}\text { 0,6000 } \\
\text { Aceitável }\end{array}$ & $\begin{array}{c}0,2666 \\
\text { Alerta }\end{array}$ & $\begin{array}{l}1,000 \\
\text { Ideal }\end{array}$ & $\begin{array}{c}0,6666 \\
\text { Aceitável }\end{array}$ & $\begin{array}{c}0,7333 \\
\text { Aceitável }\end{array}$ & $\begin{array}{l}0,0000 \\
\text { Crítica }\end{array}$ & $\begin{array}{c}0,4666 \\
\text { Alerta }\end{array}$ & $\begin{array}{c}0,5333 \\
\text { Aceitável }\end{array}$ \\
\hline $\begin{array}{l}\text { IDS } \\
\text { econômico } \\
\text { médio }\end{array}$ & & & & & & & & $\begin{array}{l}0,3890 \\
\text { Alerta }\end{array}$ \\
\hline
\end{tabular}

Legenda: AFR - Afrânio; CAB - Cabrobó; DOR - Dormentes; IDS - Índice de Desenvolvimento Sustentável; IDSM - Índice de Desenvolvimento Sustentável para Municípios; LAG - Lagoa Grande; ORO - Orocó; PET - Petrolina; SBV - Santa Maria da Boa Vista; RD - região de desenvolvimento; RD SF - Região de Desenvolvimento do Sertão do São Francisco.

\section{Dimensão social}

Para Sachs (1993), das cinco dimensões (social, econômica, ecológica, espacial e cultural) apresentadas por ele como essenciais para o planejamento do desenvolvimento, a sustentabilidade social é o que se entende como a criação de um processo de desenvolvimento que seja sustentado por outro crescimento e subsidiado por outra visão do que seja uma sociedade boa. Tendo como meta principal construir uma civilização com maior equidade na distribuição de renda e de bens, de modo a reduzir as diferenças entre os padrões de vida dos ricos e dos pobres. 
Os índices de desenvolvimento sustentável da dimensão social visam a expressar um conjunto de informações sobre a qualidade de vida da população, à satisfação das necessidades humanas, à justiça social, o nível de educação e às condições básicas à sobrevivência humana (Macêdo et al., 2011).

A inter-relação da dimensão social aqui proposta com a dimensão espacial coube no sentido de melhor avaliar as condições populacionais e sua organização rural-urbana, como mecanismo de avaliação do Índice de Sustentabilidade do Desenvolvimento Social dos Municípios das Regiões de Desenvolvimento do Sertão de Itaparica (Tabela 6) e Sertão do São Francisco (Tabela 7), em Pernambuco. Visto que o crescimento da taxa de urbanização tem sido consequência do êxodo rural ocasionado pela degradação e ausência dos recursos naturais e a falta de políticas públicas assistencialistas. A migração do campo para cidade é acompanhada de diversos impactos na sua grande maioria negativos para a população principalmente, quando ocorre sem o planejamento urbano necessário que impossibilita manter a qualidade de vida das pessoas (Araújo e Morais, 2014).

Tabela 6. Índice de Desenvolvimento Sustentável para Municípios Social da Região de Desenvolvimento do Sertão de Itaparica-PE.

\begin{tabular}{|c|c|c|c|c|c|c|c|c|}
\hline \multicolumn{9}{|c|}{ IDSM - Social RD Sertão de Itaparica } \\
\hline Indicadores & BSF & CAR & FLO & ITA & JAT & PET & TAC & RD ITA \\
\hline $\begin{array}{l}\text { Densidade } \\
\text { demográfica } \\
(\text { hab./km²) }\end{array}$ & $\begin{array}{l}0,9284 \\
\text { Ideal }\end{array}$ & $\begin{array}{l}0,9125 \\
\text { Ideal }\end{array}$ & $\begin{array}{l}1,000 \\
\text { Ideal }\end{array}$ & $\begin{array}{l}0,9497 \\
\text { Ideal }\end{array}$ & $\begin{array}{l}0,0000 \\
\text { Crítica }\end{array}$ & $\begin{array}{c}0,4619 \\
\text { Alerta }\end{array}$ & $\begin{array}{l}0,777 \\
\text { Ideal }\end{array}$ & $\begin{array}{c}0,7185 \\
\text { Aceitável }\end{array}$ \\
\hline $\begin{array}{l}\text { Taxa de } \\
\text { urbanização }\end{array}$ & $\begin{array}{l}0,3343 \\
\text { Alerta }\end{array}$ & $\begin{array}{c}1,000 \\
\text { Ideal } \\
\end{array}$ & $\begin{array}{l}0,2449 \\
\text { Crítica } \\
\end{array}$ & $\begin{array}{l}0,0000 \\
\text { Crítica }\end{array}$ & $\begin{array}{c}0,607 \\
\text { Aceitável }\end{array}$ & $\begin{array}{l}0,1788 \\
\text { Crítica } \\
\end{array}$ & $\begin{array}{c}0,6346 \\
\text { Aceitável }\end{array}$ & $\begin{array}{l}0,4285 \\
\text { Alerta }\end{array}$ \\
\hline $\begin{array}{l}\text { Esperança de } \\
\text { vida ao nascer }\end{array}$ & $\begin{array}{c}1,0000 \\
\text { Ideal }\end{array}$ & $\begin{array}{c}0,6027 \\
\text { Aceitável }\end{array}$ & $\begin{array}{c}0,8781 \\
\text { Ideal }\end{array}$ & $\begin{array}{l}0,0158 \\
\text { Critica } \\
\end{array}$ & $\begin{array}{c}0,8781 \\
\text { Ideal } \\
\end{array}$ & $\begin{array}{c}0,6027 \\
\text { Aceitável }\end{array}$ & $\begin{array}{l}0,0000 \\
\text { Crítica }\end{array}$ & $\begin{array}{c}0,5682 \\
\text { Aceitável }\end{array}$ \\
\hline $\begin{array}{l}\text { Taxa de } \\
\text { mortalidade } \\
\text { infantil }\end{array}$ & $\begin{array}{l}1,0000 \\
\text { Ideal }\end{array}$ & $\begin{array}{c}0,6397 \\
\text { Aceitável }\end{array}$ & $\begin{array}{l}0,8897 \\
\text { Ideal }\end{array}$ & $\begin{array}{l}0,0220 \\
\text { Crítica }\end{array}$ & $\begin{array}{l}0,8897 \\
\text { Ideal }\end{array}$ & $\begin{array}{l}\text { 0,6397 } \\
\text { Aceitável }\end{array}$ & $\begin{array}{l}0,000 \\
\text { Crítica }\end{array}$ & $\begin{array}{c}0,5830 \\
\text { Aceitável }\end{array}$ \\
\hline $\begin{array}{l}\text { Índice de } \\
\text { Desenvolvimento } \\
\text { Humano } \\
\text { Municipal - IDHM }\end{array}$ & $\begin{array}{l}0,9583 \\
\text { Ideal }\end{array}$ & $\begin{array}{l}0,0000 \\
\text { Crítica }\end{array}$ & $\begin{array}{c}0,7361 \\
\text { Ideal }\end{array}$ & $\begin{array}{l}0,3055 \\
\text { Alerta }\end{array}$ & $\begin{array}{l}1,000 \\
\text { Ideal }\end{array}$ & $\begin{array}{c}0,6944 \\
\text { Aceitável }\end{array}$ & $\begin{array}{l}0,0000 \\
\text { Crítica }\end{array}$ & $\begin{array}{c}0,5278 \\
\text { Aceitável }\end{array}$ \\
\hline \multicolumn{9}{|c|}{ Escolarização (pessoas de 10 anos ou mais por nível de instrução \%) } \\
\hline $\begin{array}{l}\text { Sem instrução e } \\
\text { fundamental } \\
\text { incompleto }\end{array}$ & $\begin{array}{l}0,7837 \\
\text { Ideal }\end{array}$ & $\begin{array}{l}0,2048 \\
\text { Crítica }\end{array}$ & $\begin{array}{l}1,0000 \\
\text { Ideal }\end{array}$ & $\begin{array}{l}0,7097 \\
\text { Ideal }\end{array}$ & $\begin{array}{c}\text { 0,5178 } \\
\text { Aceitável }\end{array}$ & $\begin{array}{c}0,6623 \\
\text { Aceitável }\end{array}$ & $\begin{array}{l}0,0000 \\
\text { Crítica }\end{array}$ & $\begin{array}{c}0,5541 \\
\text { Aceitável }\end{array}$ \\
\hline $\begin{array}{l}\text { Fundamental } \\
\text { completo e } \\
\text { médio } \\
\text { incompleto }\end{array}$ & $\begin{array}{c}\text { 0,6880 } \\
\text { Aceitável }\end{array}$ & $\begin{array}{c}0,5451 \\
\text { Aceitável }\end{array}$ & $\begin{array}{c}0,5960 \\
\text { Aceitável }\end{array}$ & $\begin{array}{l}1,0000 \\
\text { Ideal }\end{array}$ & $\begin{array}{l}0,2336 \\
\text { Crítica }\end{array}$ & $\begin{array}{c}0,4392 \\
\text { Alerta }\end{array}$ & $\begin{array}{l}0,0000 \\
\text { Crítica }\end{array}$ & $\begin{array}{c}0,5003 \\
\text { Aceitável }\end{array}$ \\
\hline $\begin{array}{l}\text { Médio completo } \\
\text { e superior } \\
\text { Incompleto }\end{array}$ & $\begin{array}{c}\text { 0,6663 } \\
\text { Aceitável }\end{array}$ & $\begin{array}{l}0,1393 \\
\text { Crítica }\end{array}$ & $\begin{array}{l}0,8346 \\
\text { Ideal }\end{array}$ & $\begin{array}{l}1,0000 \\
\text { Ideal }\end{array}$ & $\begin{array}{c}0,6623 \\
\text { Aceitável }\end{array}$ & $\begin{array}{c}0,5343 \\
\text { Aceitável }\end{array}$ & $\begin{array}{l}0,0000 \\
\text { Crítica }\end{array}$ & $\begin{array}{c}0,5481 \\
\text { Aceitável }\end{array}$ \\
\hline $\begin{array}{l}\text { Superior } \\
\text { completo }\end{array}$ & $\begin{array}{l}, 0000 \\
\text { Ideal }\end{array}$ & $\begin{array}{l}0,0380 \\
\text { Crítica } \\
\end{array}$ & $\begin{array}{c}0,7717 \\
\text { Ideal }\end{array}$ & $\begin{array}{c}0,5117 \\
\text { Aceitável }\end{array}$ & $\begin{array}{c}0,5734 \\
\text { Aceitável }\end{array}$ & $\begin{array}{c}0,6256 \\
\text { Aceitável }\end{array}$ & $\begin{array}{l}0,0000 \\
\text { Crítica }\end{array}$ & $\begin{array}{c}0,5029 \\
\text { Aceitável }\end{array}$ \\
\hline $\begin{array}{l}\text { Estabelecimentos } \\
\text { de Saúde (SUS) }\end{array}$ & $\begin{array}{c}0,8571 \\
\text { Ideal }\end{array}$ & $\begin{array}{c}0,8571 \\
\text { Ideal } \\
\end{array}$ & $\begin{array}{c}0,7142 \\
\text { Ideal } \\
\end{array}$ & $\begin{array}{l}0,0000 \\
\text { Crítica } \\
\end{array}$ & $\begin{array}{l}1,000 \\
\text { Ideal } \\
\end{array}$ & $\begin{array}{c}1,0000 \\
\text { Ideal }\end{array}$ & $\begin{array}{c}0,7142 \\
\text { Ideal } \\
\end{array}$ & \begin{tabular}{|c|}
0,7347 \\
Aceitável \\
\end{tabular} \\
\hline IDS social médio & & & & & & & & \begin{tabular}{|c|}
0,5666 \\
Aceitável \\
\end{tabular} \\
\hline
\end{tabular}

Legenda: BSF - Belém de São Francisco; CAR - Carnaubeira da Penha; IDS - Índice de Desenvolvimento Sustentável; IDSM - Índice de Desenvolvimento Sustentável para Municípios; FLO - Floresta; ITA - Itacuruba; JAT - Jatobá; PET - Petrolândia; TAC - Tacaratu; RD - região de desenvolvimento; RD ITA - Região de Desenvolvimento do Sertão de Itaparica. 
Tabela 7. Índice de Desenvolvimento Sustentável para Municípios Social da Região de Desenvolvimento do Sertão do São Francisco-PE.

\begin{tabular}{|c|c|c|c|c|c|c|c|c|}
\hline \multicolumn{8}{|c|}{ IDSM - Social RD Sertão do São Francisco } & \\
\hline Indicadores & AFR & CAB & DOR & LAG & ORO & PET & SBV & RD SF \\
\hline $\begin{array}{l}\text { Densidade } \\
\text { Demográfica } \\
\left(\mathrm{hab} . / \mathrm{km}^{2}\right)\end{array}$ & $\begin{array}{l}0,985 \\
\text { Ideal }\end{array}$ & $\begin{array}{c}0,8575 \\
\text { Ideal }\end{array}$ & $\begin{array}{c}1,0000 \\
\text { Ideal }\end{array}$ & $\begin{array}{c}0,9759 \\
\text { Ideal }\end{array}$ & $\begin{array}{c}0,7614 \\
\text { Ideal }\end{array}$ & $\begin{array}{l}0,0000 \\
\text { Crítica }\end{array}$ & $\begin{array}{c}0,9599 \\
\text { Ideal }\end{array}$ & $\begin{array}{c}0,7913 \\
\text { Ideal }\end{array}$ \\
\hline $\begin{array}{l}\text { Taxa de } \\
\text { Urbanização }\end{array}$ & $\begin{array}{l}1,000 \\
\text { Ideal }\end{array}$ & $\begin{array}{c}0,2531 \\
\text { Alerta }\end{array}$ & $\begin{array}{c}0,9718 \\
\text { Ideal }\end{array}$ & $\begin{array}{c}0,6985 \\
\text { Aceitável }\end{array}$ & $\begin{array}{c}0,9587 \\
\text { Ideal }\end{array}$ & $\begin{array}{l}0,0000 \\
\text { Crítica }\end{array}$ & $\begin{array}{l}0,8935 \\
\text { Ideal }\end{array}$ & \begin{tabular}{|c|}
0,5452 \\
Aceitável
\end{tabular} \\
\hline $\begin{array}{l}\text { Esperança de Vida } \\
\text { ao Nascer }\end{array}$ & $\begin{array}{c}0,5996 \\
\text { Aceitável }\end{array}$ & $\begin{array}{c}0,7248 \\
\text { Ideal } \\
\end{array}$ & $\begin{array}{l}0,3844 \\
\text { Alerta } \\
\end{array}$ & $\begin{array}{l}0,0000 \\
\text { Crítica }\end{array}$ & $\begin{array}{c}0,649 \\
\text { Aceitável }\end{array}$ & $\begin{array}{c}1,0000 \\
\text { Ideal }\end{array}$ & $\begin{array}{c}0,7248 \\
\text { Ideal }\end{array}$ & $\begin{array}{c}0,5832 \\
\text { Aceitável }\end{array}$ \\
\hline $\begin{array}{l}\text { Taxa de } \\
\text { mortalidade } \\
\text { (infantil) }\end{array}$ & $\begin{array}{c}0,6395 \\
\text { Aceitável }\end{array}$ & $\begin{array}{c}0,7558 \\
\text { Ideal }\end{array}$ & $\begin{array}{l}0,4244 \\
\text { Alerta }\end{array}$ & $\begin{array}{l}0,0000 \\
\text { Crítica }\end{array}$ & $\begin{array}{c}0,686 \\
\text { Aceitável }\end{array}$ & $\begin{array}{l}1,0000 \\
\text { Ideal }\end{array}$ & $\begin{array}{c}0,7558 \\
\text { Ideal }\end{array}$ & $\begin{array}{c}0,6087 \\
\text { Aceitável }\end{array}$ \\
\hline $\begin{array}{l}\text { Índice de } \\
\text { Desenvolvimento } \\
\text { Humano Municipal } \\
\text { - IDHM }\end{array}$ & $\begin{array}{l}0,0000 \\
\text { Crítica }\end{array}$ & $\begin{array}{l}0,3211 \\
\text { Alerta }\end{array}$ & $\begin{array}{l}0,0091 \\
\text { Crítica }\end{array}$ & $\begin{array}{l}0,0825 \\
\text { Crítica }\end{array}$ & $\begin{array}{l}0,2018 \\
\text { Crítica }\end{array}$ & $\begin{array}{l}1,0000 \\
\text { Ideal }\end{array}$ & $\begin{array}{l}0,0183 \\
\text { Crítica }\end{array}$ & $\begin{array}{l}0,2332 \\
\text { Alerta }\end{array}$ \\
\hline \multicolumn{9}{|c|}{ Escolarização-Pessoas de 10 anos ou mais por nível de instrução (\%) } \\
\hline $\begin{array}{l}\text { Sem instrução e } \\
\text { fundamental } \\
\text { incompleto }\end{array}$ & $\begin{array}{l}0,0000 \\
\text { Crítica }\end{array}$ & $\begin{array}{l}0,3357 \\
\text { Alerta }\end{array}$ & $\begin{array}{l}0,0493 \\
\text { Crítica }\end{array}$ & $\begin{array}{l}0,3234 \\
\text { Alerta }\end{array}$ & $\begin{array}{l}0,3485 \\
\text { Alerta }\end{array}$ & $\begin{array}{l}1,0000 \\
\text { Ideal }\end{array}$ & $\begin{array}{l}0,0667 \\
\text { Crítica }\end{array}$ & $\begin{array}{c}0,3034 \\
\text { Alerta }\end{array}$ \\
\hline $\begin{array}{l}\text { Fundamental } \\
\text { completo e médio } \\
\text { incompleto }\end{array}$ & $\begin{array}{l}0,3880 \\
\text { Alerta }\end{array}$ & $\begin{array}{l}0,4980 \\
\text { Alerta }\end{array}$ & $\begin{array}{l}1,0000 \\
\text { Ideal }\end{array}$ & $\begin{array}{c}0,5225 \\
\text { Aceitável }\end{array}$ & $\begin{array}{c}0,5596 \\
\text { Aceitável }\end{array}$ & 0,0000 & $\begin{array}{c}0,9682 \\
\text { Ideal }\end{array}$ & $\begin{array}{c}0,5624 \\
\text { Aceitável }\end{array}$ \\
\hline $\begin{array}{l}\text { Médio completo e } \\
\text { superior } \\
\text { incompleto }\end{array}$ & $\begin{array}{l}0,0000 \\
\text { Crítica }\end{array}$ & $\begin{array}{l}0,3702 \\
\text { Alerta }\end{array}$ & $\begin{array}{c}0,2181 \\
\text { Alerta }\end{array}$ & $\begin{array}{c}0,3159 \\
\text { Alerta }\end{array}$ & $\begin{array}{c}0,4135 \\
\text { Alerta }\end{array}$ & $\begin{array}{c}1,0000 \\
\text { Ideal }\end{array}$ & 0,2078 & $\begin{array}{c}0,3608 \\
\text { Alerta }\end{array}$ \\
\hline $\begin{array}{l}\text { Superior } \\
\text { completo }\end{array}$ & $\begin{array}{l}0,0081 \\
\text { Crítica }\end{array}$ & $\begin{array}{l}0,0702 \\
\text { Crítica }\end{array}$ & $\begin{array}{l}0,0000 \\
\text { Crítica }\end{array}$ & $\begin{array}{l}0,0322 \\
\text { Crítica }\end{array}$ & $\begin{array}{l}0,0555 \\
\text { Crítica }\end{array}$ & $\begin{array}{c}1,0000 \\
\text { Ideal }\end{array}$ & $\begin{array}{l}0,0294 \\
\text { Crítica }\end{array}$ & $\begin{array}{l}0,1708 \\
\text { Critica }\end{array}$ \\
\hline $\begin{array}{l}\text { Estabelecimentos } \\
\text { de Saúde (SUS) }\end{array}$ & $\begin{array}{l}0,0281 \\
\text { Crítica }\end{array}$ & $\begin{array}{l}0,1972 \\
\text { Crítica }\end{array}$ & $\begin{array}{l}0,0000 \\
\text { Crítica }\end{array}$ & $\begin{array}{l}0,0140 \\
\text { Crítica }\end{array}$ & $\begin{array}{l}0,0000 \\
\text { Crítica }\end{array}$ & $\begin{array}{c}1,0000 \\
\text { Ideal }\end{array}$ & $\begin{array}{l}0,1268 \\
\text { Crítica }\end{array}$ & $\begin{array}{l}0,1951 \\
\text { Critica }\end{array}$ \\
\hline IDS social médio & & & & & & & & $\begin{array}{l}0,4354 \\
\text { Alerta }\end{array}$ \\
\hline
\end{tabular}

Legenda: AFR - Afrânio; Cabrobó; DOR - Dormentes; IDS - Índice de Desenvolvimento Sustentável; IDSM - Índice de Desenvolvimento Sustentável para Municípios; LAG - Lagoa Grande; ORO - Orocó; PET - Petrolândia; SBV - Santa Maria da Boa Vista; RD - região de desenvolvimento; RD SF - Região de Desenvolvimento do Sertão do São Francisco.

Nesse contexto, os Índices de Desenvolvimento Sustentável para Municípios do Indicador da densidade demográfica para os municípios da Região de Desenvolvimento do Sertão de Itaparica mostram uma performance Ideal, excetuando-se os municípios de Jatobá e Petrolândia, com uma performance Crítica e Alerta respectivamente (Tabela 6). Na Região de Desenvolvimento do Sertão do São Francisco, 85,71\% dos municípios apresentaram uma performance Ideal, apenas Petrolina apresentou uma performance segundo o modelo Crítica (Tabela 7).

O Índice de Desenvolvimento Sustentável da taxa de urbanização para a Região de Desenvolvimento do Sertão de Itaparica cerca de 42,86 \% dos municípios apresentaram uma performance Crítica. 0 município de Belém do São Francisco foi classificado como Alerta, apenas os municípios de Jatobá e Tacaratu foram classificados como Aceitável (Tabela 6). Os municípios da Região de Desenvolvimento do Sertão do São Francisco obtiveram uma performance em geral Ideal e Aceitável. Os municípios de Cabrobó e 
Petrolina apresentam performances Alerta e Crítica, respectivamente, quanto ao crescente aumento da sua população urbana (Tabela 7).

A esperança de vida ao nascer é um indicador da qualidade de vida de um país, região ou município. Quanto maiores os níveis de esperança de vida ao nascer, melhores as condições de vida e de saúde da região. Esse índice é de fundamental importância por subsidiar os processos de planejamento, gestão e avaliação de políticas de saúde (DATASUS, 2016).

Como se pode observar, o Índice de Desenvolvimento Sustentável para Municípios para a esperança de vida ao nascer dos municípios de Belém do São Francisco, Floresta e Jatobá obtiveram os melhores índices, classificando-se como Ideais. Carnaubeira da Penha e Petrolândia obtiveram valores Aceitáveis. Os Municípios de Itacuruba e Tacaratu classificaram-se como Críticos (Tabela 6).

Na Região de Desenvolvimento do Sertão do São Francisco (Tabela 7), os municípios de Afrânio e Orocó apresentam uma performance Aceitável com relação à esperança de vida ao nascer. Os municípios de Cabrobó, Petrolina e Santa Maria da Boa Vista, tiveram um melhor desempenho obtendo um Índice de Desenvolvimento Sustentável para Municípios da esperança de vida Ideal, porém, se faz necessário uma atenção para os Municípios de Lagoa Grande e Dormentes que apresentam performances Alerta e Crítica, respectivamente.

A taxa de mortalidade infantil estima o risco de um nascido vivo morrer durante o seu primeiro ano de vida. Altas taxas de mortalidade infantil refletem, de maneira geral, baixos níveis de saúde, de desenvolvimento socioeconômico e de condições de vida (MS, 2016).

Cerca de 42,85\% dos municípios da Região de Desenvolvimento do Sertão de Itaparica apresentam dados positivos no Índice de Desenvolvimento Sustentável para Municípios para a taxa de mortalidade infantil com uma performance Ideal, enquanto 28,57\% apresentam uma performance Aceitável. Já Itacuruba e Tacaratu foram classificados com uma performance Crítica, explicitando as necessidades de melhores condições de saúde e de vida para a população (Tabela 6).

0 índice para a taxa de mortalidade infantil na Região de Desenvolvimento do Sertão do São Francisco (Tabela 7) nos mostra que os municípios de Petrolina, Santa Maria da Boa Vista e Cabrobó, representam para o a região uma performance Ideal, enquanto Dormentes e Lagoa Grande foram classificados como um sinal de Alerta e Crítica, respectivamente.

O Índice de Desenvolvimento Humano Municipal (IDHM) é um índice composto que agrega três das mais importantes dimensões do desenvolvimento humano: a oportunidade de viver uma vida longa e saudável, de ter acesso ao conhecimento e ter um padrão de vida que garanta as necessidades básicas, representadas pela saúde, educação e renda (Brasil, 2013).

Ao compararmos os Índices de Desenvolvimento Sustentável Municipal para indicador o IDHM da Região de Desenvolvimento do Sertão de Itaparica com a Região de Desenvolvimento da Sertão do São Francisco, podemos visualizar um grande contraste no que se diz respeito ao desenvolvimento humano. Cerca de $57,14 \%$ dos municípios da Região de Desenvolvimento do Sertão de Itaparica apresentaram para esse indicador uma performance variando de Ideal a Aceitável, enquanto 85,71\% dos municípios da Região de Desenvolvimento do Sertão do São Francisco apresentam uma performance Crítica ou Alerta. Pode-se assim concluir que, as necessidades básicas da população podem estar sendo negligenciadas. 
Segundo o art. 205, da Constituição Federal Brasileira:

[...] a Educação é direito de todos e dever do Estado e da família, será promovida e incentivada com a colaboração da sociedade, visando ao pleno desenvolvimento da pessoa, seu preparo para o exercício da cidadania e sua qualificação para o trabalho (Brasil, 1988).

O Índice de Desenvolvimento Sustentável para Municípios Social para a Educação foi avaliado levando em consideração a porcentagem de pessoas de 10 anos ou mais por seu nível de instrução, que variou de sem instrução ao Ensino Superior completo. Esse índice é a base para o desenvolvimento sustentável de uma região, pois é através do acesso à Educação que a população pode desenvolver suas habilidades, suas capacidades cognitivas, que possibilitam o seu desenvolvimento e inserção no mercado de trabalho, que se torna cada vez mais especializado. Através da Educação, o cidadão torna-se mais consciente de seus direitos e deveres perante a sociedade exercendo, assim, a sua cidadania.

Analisando os dados do nível de escolaridade da população para as regiões de desenvolvimento, observamos a dimensão das desigualdades. A Região de Desenvolvimento do Sertão de Itaparica apresenta dados mais animadores, com um bom desempenho para as variáveis do Ensino Médio completo ao Ensino Superior completo. Para essa região os municípios de Carnaubeira da Penha e Tacaratu estão em estado Crítico.

Quanto ao nível de escolaridade da Região de Desenvolvimento do Sertão do São Francisco, apenas o município de Petrolina apresentou uma performance Ideal para os graus do Ensino Médio completo ao Ensino Superior completo (Tabela 7). Esse desempenho deve-se principalmente pelo fato do município possuir Centros Universitários e Tecnológicos, possibilitando que a população tenha acesso ao Ensino Superior, gerando mão-de-obra qualificada necessária para suprir a demanda local. A presença desses Centros favorece a população dos municípios vizinhos, o que possibilitará a longo prazo a melhoria do nível de grau de instrução da região, sendo este um fator que refletirá positivamente na sustentabilidade local.

Porém hoje, a realidade de Petrolina não é a mesma para os demais municípios que compõem a Região de Desenvolvimento do Sertão do São Francisco. Cerca de 57,14\% dos municípios estão em estado de Alerta, e 28,57\% em estado Crítico de Educação para as variáveis do Ensino Médio ao Ensino Superior incompleto. Os dados para o Ensino Superior completo são ainda mais alarmantes, pois apenas Petrolina não está em um estado Crítico. A partir da análise desses dados, pode-se concluir que é urgente a necessidade de maiores incentivos públicos que sejam direcionados para educação de jovens e adultos na região.

Outra disparidade entre as duas regiões são as ofertas de serviços de saúde. $\mathrm{Na}$ Região de Desenvolvimento do Sertão de Itaparica, apenas o Município de Itacuruba está em um estado Crítico, enquanto os demais municípios obtiveram um índice Ideal de acesso aos serviços de saúde públicos. Em contradição, os municípios da Região de Desenvolvimento do Sertão do São Francisco, apresentaram uma performance Crítica e em Alerta, excetuando apenas Petrolina.

Ao analisarmos o índice de desenvolvimento sustentável médio para a dimensão social as duas regiões que compõe parte da região do Submédio São Francisco no estado de Pernambuco, é possível verificar o contraste na qualidade de vida da população.

A Região de Desenvolvimento do Sertão de Itaparica por apresentar os melhores índices obteve uma performance Aceitável, enquanto a Região de Desenvolvimento do Sertão do São Francisco está em uma situação de Alerta, condizentes com os baixos índices 
para a Educação e Saúde, que comprometem a dimensão social podendo ser considerada como insustentável.

\section{Dimensão político-institucional}

A Dimensão político-institucional faz referência à capacidade da população de exercer sua cidadania através da sua participação político eleitoral, corroborando com as atitudes necessárias para o desenvolvimento sustentável da localidade.

Segundo Martins e Cândido (2008) esse índice permite uma avaliação dos níveis de sustentabilidade, tendo como principal contribuição um conjunto de informações que servirão para a busca de alternativas que visem ao desenvolvimento local.

Os dados para Índice de Desenvolvimento Sustentável para Municípios da dimensão político-institucional para a Região de Desenvolvimento do Sertão de Itaparica (Tabela 8) e Região de Desenvolvimento do Sertão do São Francisco (Tabela 9) mostraram que a participação social nas eleições apresentou um estado de Alerta e Crítico, respectivamente.

Para a Região de Desenvolvimento do Sertão de Itaparica apenas o município de Petrolândia foi classificado como Ideal e Floresta com um índice Aceitável. Na Região de Desenvolvimento do Sertão do São Francisco, apenas o município de Petrolina obteve, segundo o modelo, uma performance Ideal (Tabela 8 e 9).

A ausência da população na participação eleitoral, impossibilita as reivindicações por melhores condições de vida, pois só através do voto consciente a população pode escolher bem os seus representantes e assim lutar por uma maior equidade social.

A presença de conselhos municipais, assim como a participação eleitoral, expressa uma maior mobilização da sociedade pela participação da vida institucional nos municípios (Martins e Cândido, 2008). A ausência de conselhos limita a participação social e a busca por mais direitos seja ele para: Saúde, Educação, proteção aos idosos, etc. Para as duas regiões em analise os índices dos números de conselhos municipais apresentaram uma performance que variou de Crítica a um estado de Alerta, respectivamente.

A dependência dos municípios em relação às transferências Intergovernamentais da União, torna o desenvolvimento sustentável mais vulnerável. Como índice de avaliação do desenvolvimento sustentável municipal, essa dependência representa um fator negativo.

A Região de Desenvolvimento do Sertão de Itaparica (Tabela 8) mostra-se relativamente dependente dessas transferências, sendo Floresta e Petrolândia os municípios que apresentam o estado mais Crítico. Já em contrapartida, os municípios da Região de Desenvolvimento do Sertão do São Francisco (Tabela 9) apresentam uma performance Ideal, excetuando-se apenas o município de Petrolina, que apresenta uma forte dependência das transferências da União.

Os dados do IDS Índice de Desenvolvimento Sustentável médio político-institucional das regiões demostraram um estado de Alerta para as duas regiões de desenvolvimento. Obtendo nesta dimensão um índice muito próximo à Região de Desenvolvimento do Sertão de Itaparica com 0,4447 e com 0,4472 a Região de Desenvolvimento do Sertão do São Francisco, podendo-se concluir que para essa dimensão as duas regiões apresentam um perfil frágil insustentável de desenvolvimento. 
Tabela 8. Índice de Desenvolvimento Sustentável para Municípios da dimensão Político-institucional da Região de Desenvolvimento do Sertão de Itaparica-PE.

\begin{tabular}{|c|c|c|c|c|c|c|c|c|}
\hline \multicolumn{8}{|c|}{ IDSM Político-institucional RD Sertão de Itaparica } & \multirow[b]{2}{*}{ RD ITA } \\
\hline Indicadores & BSF & CAR & FLO & ITA & JAT & PET & TAC & \\
\hline $\begin{array}{l}\text { Participação nas } \\
\text { eleições }\end{array}$ & $\begin{array}{l}0,4019 \\
\text { Alerta }\end{array}$ & $\begin{array}{l}0,2188 \\
\text { Alerta }\end{array}$ & $\begin{array}{c}0,6637 \\
\text { Aceitável }\end{array}$ & $\begin{array}{l}0,0000 \\
\text { Crítica }\end{array}$ & $\begin{array}{c}0,2361 \\
\text { Alerta }\end{array}$ & $\begin{array}{c}0,7554 \\
\text { Ideal }\end{array}$ & $\begin{array}{c}0,3714 \\
\text { Alerta }\end{array}$ & $\begin{array}{c}0,3782 \\
\text { Alerta }\end{array}$ \\
\hline $\begin{array}{l}\text { Número de } \\
\text { Conselhos } \\
\text { Municipais }\end{array}$ & $\begin{array}{c}0,1667 \\
\text { Alerta }\end{array}$ & $\begin{array}{l}0,0000 \\
\text { Crítica }\end{array}$ & $\begin{array}{c}1,0000 \\
\text { Ideal }\end{array}$ & $\begin{array}{c}0,3333 \\
\text { Alerta }\end{array}$ & $\begin{array}{c}0,6667 \\
\text { Aceitável }\end{array}$ & $\begin{array}{l}0,3333 \\
\text { Alerta }\end{array}$ & $\begin{array}{c}0,3333 \\
\text { Alerta }\end{array}$ & $\begin{array}{l}0,4048 \\
\text { Alerta }\end{array}$ \\
\hline $\begin{array}{l}\text { Transferências } \\
\text { Intergovernamentais } \\
\text { da União (Reais) }\end{array}$ & $\begin{array}{c}0,6275 \\
\text { Aceitável }\end{array}$ & $\begin{array}{c}0,8758 \\
\text { Ideal }\end{array}$ & $\begin{array}{l}0,2441 \\
\text { Crítica }\end{array}$ & $\begin{array}{c}1,0000 \\
\text { Ideal }\end{array}$ & $\begin{array}{c}0,5968 \\
\text { Aceitável }\end{array}$ & $\begin{array}{l}0,0000 \\
\text { Crítica }\end{array}$ & $\begin{array}{c}0,5142 \\
\text { Aceitável }\end{array}$ & $\begin{array}{c}0,5512 \\
\text { Aceitável }\end{array}$ \\
\hline $\begin{array}{l}\text { IDS político- } \\
\text { institucional médio }\end{array}$ & & & & & & & & \begin{tabular}{|l|}
0,4447 \\
Alerta
\end{tabular} \\
\hline
\end{tabular}

Legenda: BSF - Belém de São Francisco; CAR - Carnaubeira da Penha; FLO - Floresta; IDS - Índice de Desenvolvimento Sustentável; IDSM - Índice de Desenvolvimento Sustentável para Municípios; ITA - Itacuruba; JAT - Jatobá; PET - Petrolândia; TAC - Tacaratu; RD - região de desenvolvimento; RD ITA - Região de Desenvolvimento do Sertão de Itaparica.

Tabela 9. IDSM Índice de Desenvolvimento Sustentável para Municípios da dimensão Político-institucional da RD Região de Desenvolvimento do Sertão do São Francisco-PE.

\begin{tabular}{|c|c|c|c|c|c|c|c|c|}
\hline \multicolumn{8}{|c|}{ IDSM Político-institucional RD Sertão do São Francisco } & \multirow[b]{2}{*}{ RD SF } \\
\hline Indicadores & AFR & CAB & DOR & LAG & ORO & PET & SBV & \\
\hline Participação nas Eleições & 0,0258 & 0,0627 & 0,0202 & 0,0340 & 0,0000 & 1,0000 & 0,0878 & 0,1758 \\
\hline & Crítica & Crítica & Crítica & Crítica & Crítica & Ideal & Crítica & Crítico \\
\hline Número de Conselhos & 0,5000 & 0,2500 & 0,2500 & 0,2500 & 0,0000 & 1,0000 & 0,2500 & 0,3571 \\
\hline Municipais & Alerta & Crítica & Crítica & Crítica & Crítica & Ideal & Crítica & Alerta \\
\hline $\begin{array}{l}\text { Transferências } \\
\text { Intergovernamentais da } \\
\text { União (Reais) }\end{array}$ & $\begin{array}{c}0,9464 \\
\text { Ideal }\end{array}$ & $\begin{array}{c}0,9258 \\
\text { Ideal }\end{array}$ & $\begin{array}{c}0,9625 \\
\text { Ideal }\end{array}$ & $\begin{array}{c}0,9222 \\
\text { Ideal }\end{array}$ & $\begin{array}{c}1,0000 \\
\text { Ideal }\end{array}$ & $\begin{array}{l}0,0000 \\
\text { Crítica }\end{array}$ & $\begin{array}{c}0,9046 \\
\text { Ideal }\end{array}$ & $\begin{array}{c}0,8088 \\
\text { Ideal }\end{array}$ \\
\hline $\begin{array}{l}\text { IDS político-institucional } \\
\text { médio }\end{array}$ & & & & & & & & $\begin{array}{l}0,4472 \\
\text { Alerta }\end{array}$ \\
\hline
\end{tabular}

Legenda: AFR - Afrânio; Cabrobó; DOR - Dormentes; IDS - Índice de Desenvolvimento Sustentável; IDSM - Índice de Desenvolvimento Sustentável para Municípios; LAG - Lagoa Grande; ORO - Orocó; PET - Petrolândia; SBV - Santa Maria da Boa Vista; RD - Região de Desenvolvimento; RD ITA Região de Desenvolvimento do Sertão do São Francisco.

\section{Índice final}

Para esse cálculo levou-se em consideração cada uma das quatro dimensões do desenvolvimento sustentável proposto pela metodologia para que fosse possível obter por meio da média aritmética o Índice de Desenvolvimento Sustentável final das Regiões de Desenvolvimento do Estado de Pernambuco (Tabela 10). 
Tabela 10. Índice de Desenvolvimento Sustentável Final por Região de Desenvolvimento, Estado de Pernambuco.

\begin{tabular}{|l|c|c|}
\hline Dimensão & Índice - RD Sertão de Itaparica & Índice - RD Sertão do São Francisco \\
\hline \multirow{2}{*}{ Ambiental } & 0,4895 & 0,3870 \\
& Alerta & Alerta \\
\hline \multirow{2}{*}{ Econômica } & 0,5113 & 0,3890 \\
& Aceitável & Alerta \\
\hline \multirow{2}{*}{ Social } & 0,5666 & 0,4354 \\
& Aceitável & Alerta \\
\hline \multirow{2}{*}{ Político-Institucional } & 0,4447 & 0,4472 \\
& Alerta & Alerta \\
\hline \multirow{2}{*}{ IDS Final } & $\mathbf{0 , 5 0 3 0}$ & $\mathbf{0 , 4 1 4 7}$ \\
& Aceitável & Alerta \\
\hline
\end{tabular}

Legenda: IDS - Índice de Desenvolvimento Sustentável; RD - Região de Desenvolvimento.

Como resultado do Índice de Desenvolvimento Sustentável final, obtivemos um valor de 0,5030, correspondendo a uma performance Aceitável de desenvolvimento sustentável para a Região de Desenvolvimento do Sertão de Itaparica, mas ainda longe do considerado Ideal. Como pode ser observado na tabela acima, as dimensões ambiental e político-institucional encontram-se em estado de Alerta, sendo estas duas esferas de grande importância para a sustentabilidade do desenvolvimento local.

A Região de Desenvolvimento do Sertão do São Francisco obteve um Índice de Desenvolvimento Sustentável final de 0,4147 registrando uma performance de Alerta. Os índices médios para cada uma das dimensões abordadas refletiram o mesmo quadro.

\section{Conclusão}

A utilização de índices têm sido ferramentas úteis, apesar de apresentarem algumas deficiências, eles possibilitam inferir e comparar o grau de sustentabilidade a partir de dados estatísticos, e passam a servir como guias para aplicação de políticas públicas que possibilitam a melhoria da qualidade dos serviços prestados à população.

O índice de Desenvolvimento Sustentável Municipal possibilitou avaliar o nível de sustentabilidade para duas regiões de desenvolvimento do estado de Pernambuco, as Regiões de Desenvolvimento do Sertão de Itaparica e do Sertão do São Francisco. Regiões estas compostas por sete municípios cada, totalizando catorze municípios, situadas em uma região de grande vulnerabilidade ambiental e marcada por profundas desigualdades sociais, o Semiárido.

A partir da geração do Índice de Desenvolvimento Sustentável Ambiental, foi possível observar que as duas regiões estão em estado de Alerta. Medidas para mitigar esse quadro devem ser aplicadas, visando à preservação e à conservação, sobretudo, dos recursos hídricos. Além do controle e manejo dos efluentes gerados, a fim de garantir a sustentabilidade dos ecossistemas aquáticos, bem como seu uso para consumo humano.

o Índice de Desenvolvimento Sustentável Econômico, mostra a necessidade de novos investimentos e estímulo em ambas regiões. Apesar da Região de Desenvolvimento de Itaparica apresentar uma situação Aceitável, ainda se encontra longe do ideal para o ponto de vista da sustentabilidade. Já a Região de Desenvolvimento do Sertão do São Francisco, apesar de ter um grande desenvolvimento no município de Petrolina impulsionado pelo desenvolvimento da agricultura irrigada, tem apresentado índices de desenvolvimento muito abaixo do considerado sustentável, pois como pode ser observado, os demais municípios vizinhos não tem acompanhado o panorama econômico atual. 
A qualidade de vida da população pode ser vista como um termômetro do desenvolvimento sustentável. O Índice de Desenvolvimento Sustentável Social obtido para as regiões demonstra o quanto ainda há carência de incentivos às áreas de Educação e z Saúde nos municípios avaliados.

O Índice de Desenvolvimento Sustentável Político-Institucional das duas regiões classificou-se como em Alerta. Pode-se avaliar esse índice como reflexo da deficiência na educação nas duas regiões, onde o número de participantes nas eleições foi bastante crítico, demonstrando que a população tem deixado de praticar a sua cidadania, o que impossibilita a busca por melhores condições de vida.

De modo geral, o índice final da Região de Desenvolvimento do Sertão de Itaparica ficou superior ao índice final Região de Desenvolvimento do São Francisco, o que demonstra que o índice não privilegia o desenvolvimento econômico frente aos outros indicadores. Pode-se observar ainda, que há uma grande desigualdade entre os munícipios da Região de Desenvolvimento do Sertão do São Francisco, que influenciou no índice final mais baixo.

\section{Agradecimentos}

Os autores agradecem à Coordenação de Aperfeiçoamento de Pessoal de Nível Superior (CAPES) pelo apoio financeiro para esta pesquisa.

\section{Conflito de interesses}

Os autores declaram não haver conflito de interesses.

\section{Referências}

Araújo, J. A.; Morais, G. A. S. Desigualdade de renda e sua decomposição no Brasil e nas regiões brasileiras. Revista Econômica do Nordeste, v. 45, n. 4, p. 35-49, 2014.

Barbieri, J. C. Desenvolvimento sustentável: as estratégias de mudanças da Agenda 21. Petrópolis: Vozes, 1997.

Brasil. Atlas do Desenvolvimento Humano no Brasil. 2013. Disponível em: <http://www.atlasbrasil.org.br/2013/pt/o_atlas/idhm/>. Acesso em: 15 jul. 2020.

Brasil. Constituição da República Federativa do Brasil de 1988. Disponível em: <http://www.planalto.gov.br/ccivil_03/constituicao/constituicao.htm>. Acesso em: 15 jul. 2020.

Brasil. Ranking IDHM Municípios 2010. Brasil. Atlas do Desenvolvimento Humano no Brasil. 2013. Disponível em: <http://www.atlasbrasil.org.br/2013/pt/o_atlas/idhm/>. Acesso em: 15 jul. 2020.

Carvalho, M. T. M.; Caldas, L. R.; Sposto, R. M. Avaliação da sustentabilidade de habitações de interesse social a partir da especificação de materiais e elementos da edificação. Revista de Gestão Ambiental e Sustentabilidade, v. 9, n. 1, p. 1-25, 2020. https://doi.org/10.5585/geas.v9i1.17155

CHESF - Companhia Hidroelétrica do São Francisco. 1o Relatório quadrimestral 2013/2014 - Relatório 1A. Programa de Monitoramento dos Ecossistemas Aquáticos do Reservatório de Itaparica. Recife: CHESF, 2014. 
CHESF - Companhia Hidroelétrica do São Francisco. Inventário dos ecossistemas aquáticos do Baixo São Francisco. Reservatório Itaparica. 2o Relatório Anual Dezembro/2008 a Novembro/2009. Recife: CHESF, 2010.

Cipolat, C.; Ludke, Q. P.; Kraemer, E. I.; Braun, A. B.; Silva, A. F. Ações e estratégias para o desenvolvimento sustentável na América Latina Logística - ALL. Anais do VII Simpósio de Excelência em Gestão e Tecnologia, Resende, 2010.

CMMAD - Comissão Mundial Sobre o Meio Ambiente e Desenvolvimento. Nosso futuro comum. Rio de Janeiro: Fundação Getúlio Vargas, 1988.

Drahein, A. D.; Lima, E. P.; Costa, S. E. G. Ferramentas para avaliação da sustentabilidade nas operações de serviço em instituições de ensino superior. Revista de Gestão Ambiental e Sustentabilidade, v. 9, n. 1, p. 1-25, 2020. https://doi.org/10.5585/ geas.v9i1.17156

Francelino, M. R.; Fernandes-Filho, E. I.; Resende, M. Elaboração de um sistema de classificação da capacidade de suporte em ambiente semi-árido. Revista Brasileira de Engenharia Agrícola e Ambiental, v. 9, n. 1, p. 83-91, 2005. https://doi.org/10.1590/ S1415-43662005000100013

Gomes, P. P. V.; Bernardo, A.; Brito, G. Princípios de sustentabilidade: uma abordagem histórica. Anais do XXV Encontro Nacional de Engenharia de Produção, Porto Alegre, 2005.

Goulart, L. C. R.; Pietrafesa, P. A. Ações ambientais positivas e a integração de informações sustentáveis implementadas na administração pública federal. Revista Brasileira de

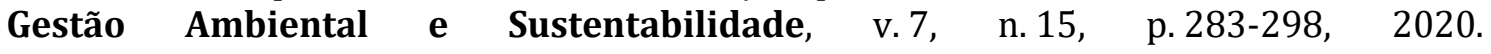
https://doi.org/10.21438/rbgas(2020)071521

Guimarães, R. P. Aterrizando un cometa: indicadores territoriales de sustentabilidad. Santiago do Chile: CEPAL/ILPES, 1998. (Serie Investigación, Documento 18/98, LC/IP/G.120).

IBGE - Instituto Brasileiro de Geografia e Estatística. Indicadores de desenvolvimento sustentável. Rio de Janeiro: IBGE, 2015. (Estudos e Pesquisas, Informação Geográfica, n. 10).

Krama, M. R. Análise dos indicadores de desenvolvimento sustentável no Brasil, usando a ferramenta painel de sustentabilidade. Curitiba, Pontifícia Universidade Católica do Paraná, 2009. (Dissertação de mestrado).

Lopes, A. E.; Rocha, A. C. T.; Lima, A. O.; Antunes, D. A.; Ferrão, E. M. G.; Oliveira Junior, A. F. Do ecodesenvolvimento ao desenvolvimento sustentável: a trajetória de conflitos e desafios para o meio ambiente. ForScience, v. 5, n. 2, e00314, 2017. https://doi.org/10.29069/forscience.2017v5n2.e314

Macêdo, N. M. M. N.; Cândido, G. A. Índice de Desenvolvimento Sustentável Local e suas influências nas políticas públicas: um estudo exploratório no Município de Alagoa GrandePB. Gestão \& Produção, v. 18, n. 3, p. 619-632, 2011. https://doi.org/10.1590/S0104530X2011000300013

Martins, M. F.; Cândido, G. A. Metodologia para construção e análise de índices de desenvolvimento sustentável: uma aplicação no Estado da Paraíba. João Pessoa: SEBRAE, 2008.

MMA - Ministério do Meio Ambiente. Caderno da Região Hidrográfica do São Francisco. Brasília: MMA, 2016. 
MS - Ministério da Saúde. Indicadores e dados básicos: Brasil, 2012 IDB-2012. Brasília: MS, 2013. Disponível em: <http://tabnet.datasus.gov.br/cgi/idb2012/matriz.htm>. Acesso em: 20 fev. 2016.

Munro, D. A. Cuidando do Planeta Terra: uma estratégia para o futuro da vida - Sumário. São Paulo: UICN, PNUMA, WWF, 1991.

Pereira, M. S.; Sauer, L.; Fagundes, M. B. B. Mensurando a sustentabilidade ambiental: uma proposta de índice para o Mato Grosso do Sul. Interações, v. 17, n. 2, p. 327-338, 2016. https://doi.org/10.20435/1984042X2016215

Ramos, C. Desenvolvimento econômico sustentável: tendências e desafios na promoção dos empregos verdes no Brasil. Textos e Debates, v. 2, n. 30, p. 23-38, 2016. https://doi.org/10.18227/2217-1448ted.v2i30.3417

Rocha, H.; Mayorga, D.; Lima, P. V. P. S.; Mayorga, I. A contribuição das parcelas do rendimento mensal domiciliar para a distribuição de renda no meio rural do Estado do Ceará. Revista de Desenvolvimento do Ceará, n. 1, 2010. Disponível em: <http://repositorio.ufc.br/bitstream/riufc/3543/1/2010_art_dmayorga.pdf>. Acesso em: 15 jul. 2020.

Sachs, I. Desenvolvimento includente, sustentável e sustentado. Rio de Janeiro: Garamond, 2004.

Sachs, I. Estratégias de transição para o século XXI: Para pensar o desenvolvimento sustentável. São Paulo: Brasiliense, 1993.

Santos, P. R.; Santana, V. V.; Santos, M. C. V.; Lopes, V. S. Breve análise da importância dos órgãos executores da política ambiental brasileira frente aos agravos ambientais em unidades de conservação. Revista Brasileira de Gestão Ambiental e Sustentabilidade, v. 7, n. 15, p. 211-223, 2020. https://doi.org/10.21438/rbgas(2020)071515

Sobral, M. C. M.; Carvalho, R. M. C. M. O.; Silva, M. M.; Melo, G. L. Uso e ocupação do solo no entorno de reservatórios no semi-árido brasileiro como fator determinante da qualidade da água. Anais do XXXII Congreso Interamericano de Ingeniería Sanitaria y Ambiental, Punta del Este, Uruguay, 2009.

Waquil, P. D.; Shneider, S.; Fileppi, E. E.; Rückert, A.; Rambo, A.; Radomsky, G.; Conterato, M. A.; Specht, S. Avaliação de desenvolvimento territorial em quatro territórios rurais no Brasil. REDES - Revista do Desenvolvimento Regional, v. 15, n. 1, p. 104-127, 2010. https://doi.org/10.17058/redes.v15i1.48

Informação da Licença: Este é um artigo Open Access distribuído sob os termos da Licença Creative Commons Attribution, que permite uso irrestrito, distribuição e reprodução em qualquer meio, desde que a obra original seja devidamente citada. 
